\title{
Localization of Tissue Transglutaminase in Human Carotid and Coronary Artery Atherosclerosis: Implications for Plaque Stability and Progression
}

\author{
Zishan A. Haroon, Thomas Wannenburg, Madhu Gupta, Charles S. Greenberg, \\ Reidar Wallin, and David C. Sane \\ Departments of Medicine and Pathology (ZAH, CSG), Duke University Medical Center, Durham, and Sections of \\ Cardiology (TW, MG, DCS) and Rheumatology (RW), Wake Forest University School of Medicine, Winston-Salem, \\ North Carolina
}

\begin{abstract}
SUMMARY: Although atherosclerosis progresses in an indolent state for decades, the rupture of plaques creates acute ischemic syndromes that may culminate in myocardial infarction and stroke. Mechanical forces and matrix metalloproteinase activity initiate plaque rupture, whereas tissue inhibitors of metalloproteinases have an important (albeit indirect) role in plaque stabilization. In this paper, an enzyme that could directly stabilize the plaque is described. Tissue transglutaminase (TG) catalyzes the formation of $\epsilon(\gamma$-glutamyl)lysine isopeptide bonds that are resistant to enzymatic, mechanical, and chemical degradation. We performed immunohistochemistry for TG in atherosclerotic human coronary and carotid arteries. TG was most prominent along the luminal endothelium and in the medium of the vessels with a distribution mirroring that of smooth muscle cells. Variable, often prominent, immunoreactivity for TG was also seen in the intima, especially in regions with significant neovascularization. Additionally, TG was detected in fibrous caps and near the "shoulder regions" of some plaques. A monoclonal antibody to the transglutaminase product $\epsilon(\gamma$-glutamyl)lysine isopeptide demonstrated co-localization with TG antigen. Transglutaminase activity was found in 6 of 14 coronary artery atherectomy samples. Cross-linking of TG substrates such as fibrinogen, fibronectin, vitronectin, collagen type I, and protease inhibitors stabilized the plaque. Furthermore, the activation of transforming growth factor-beta-1 by TG might be an additional mechanism for the promotion of plaque stabilization and progression by increasing the synthesis of extracellular matrix components. (Lab Invest 2001, 81:83-93).
\end{abstract}

$T$ he major manifestations of atherosclerosis, including stroke and myocardial infarction, are initiated by the formation of thrombus at the site of plaque rupture or erosion (Lee and Libby 1997; Shah, 1997). Disrupted plaques tend to have large lipid cores comprised of soft cholesteryl esters that redistribute the circumferential wall stress to the shoulder regions of the plaque (Davies, 1996; Falk, 1992; Richardson et al, 1989). This mechanical effect is exacerbated in plaques that have a thin fibrous cap (Loree et al, 1992) and in plaques that are only mildly to moderately stenotic because, according to Laplace's law, wall stress is directly proportional to the radius of the vessel (Lee and Kamm, 1994). The thinning of the fibrous cap may result from a reduced content of smooth muscle cells (SMC). The SMC reduction may be a result of decreased replication, reduced migra-

Received September 20, 2000.

DCS was supported by grants DK55061 and HL60774 from the National Institutes of Health. ZAH was supported by the Department of Defense grant DAMD 179717044. Additional support was from the Duke Specialized Program of Research Excellence on Breast Cancer grant P50 CA 68438 (CSG), and HL 38245 and HL 26309 (CSG).

Address reprint requests to: Dr. David C. Sane, Section of Cardiology, Wake Forest University School of Medicine, Medical Center Boulevard, Winston-Salem, NC 27157-1045. E-mail: dsane@wfubmc.edu tion into the cap, or increased apoptosis (Geng and Libby, 1995, Libby et al, 1998). SMC are the source of collagen, elastin, and glycosaminoglycans in the cap. Consequently, a reduction in the SMC content leads to weakening of the fibrous cap through loss of these matrix constituents (Davies et al, 1994).

In addition to these physical forces, proteolytic factors also affect plaque stability. An infiltration of inflammatory cells is a common feature of disrupted plaques, especially in the "shoulder regions" (Lendon et al, 1991; van der Wal et al, 1994). These inflammatory cells, primarily macrophages, express zymogen forms of matrix metalloproteinases (MMP) that, when activated, degrade the collagen and elastin components of the plaque (Galis et al, 1994; Shah et al, 1995). Activated mast cells are also increased in vulnerable plaques and secrete enzymes such as tryptase and chymase that can activate pro-MMP derived from SMC and macrophages (Kaartinen et al, 1998; Kovanen et al, 1995).

The tissue inhibitors of metalloproteinases (TIMP) are a family of specific inhibitors that regulate MMP activity by forming 1:1 complexes with MMP (Dellery et al, 1995), thereby inhibiting proteolysis-mediated rupture. Although TIMP offer protection against proteolytic destabilization, they do not directly contribute to plaque stability. In contrast, the transglutaminases are a family of 
homologous enzymes that catalyze the cross-linking of proteins by forming $\epsilon(\gamma$-glutamyl)lysine isopeptide bonds, thereby providing stability against chemical, mechanical, and proteolytic degradation to a variety of tissues (Greenberg et al, 1991).

Previous studies have suggested that tissue transglutaminase (TG) is present and active in the atherosclerotic plaque. Fibrinogen polymers, cross-linked through the $\alpha$ chain, have been detected in the intima (Shainoff and Page 1972; Valenzuela, 1992), providing indirect evidence for transglutaminase activity. The $\alpha$ chain of fibrinogen is the preferred substrate for TG, whereas factor XIIla, a plasma form of transglutaminase that has also been found in the atheroma (Romanic et al, 1998), preferentially cross-links fibrinogen $\gamma$ chains (Greenberg et al, 1991). In addition to fibrinogen, many of the other major substrates of the tissue form of the transglutaminase enzyme are prominent components of the extracellular matrix (ECM) of the atherosclerotic plaque. For these reasons, we performed a comprehensive analysis of the distribution and activity of TG in coronary and carotid artery atherosclerosis. The implications of transglutaminase expression in atherosclerotic tissues are discussed.

\section{Results}

\section{Immunoblotting for TG Antigen}

Homogenates of a segment of normal internal mammary artery, plaque obtained at carotid endarterectomy, and coronary artery tissue obtained by Directional Coronary Atherectomy were prepared as described in "Materials and Methods". Twenty-five micrograms of total protein was separated by $10 \%$ SDS-PAGE and immunoblotted with CUB 7402, a monoclonal antibody to guinea pig liver transglutaminase (GPTG). Similar results were obtained with TG100, another monoclonal antibody to TG (data not shown). Figure $1 \mathrm{~A}$ shows the immunoblots of the homogenates from four carotid plaques (lanes 1 to 4 ) and the internal mammary artery (lane 5). In all cases, the TG migrated at the expected molecular mass of 85 kd (Gentile et al, 1991). Figure 1B shows the immunoblots of the three coronary atherectomy homogenates (lanes 1 to 3 ) and the internal mammary homogenate (lane 4). One sample (lane 2) demonstrated that the predominant TG antigen migrated at $65 \mathrm{kd}$, probably because of proteolysis that occurred in vivo or in vitro (despite the use of protease inhibitors).

\section{TG and Isopeptide: Specificity of Immunohistochemistry}

The distributions of TG antigen and isopeptide were similar in coronary and carotid arteries. Figure $2 \mathrm{~A}$ shows immunohistochemistry (IHC) for the TG antigen. Figure 2B shows the distribution of the isopeptide. Figure $2 \mathrm{C}$ shows a specificity control for the $\mathrm{IHC}$, with normal mouse serum substituted for the primary antibody. There was virtually no background immunoreactivity under the conditions used for $\mathrm{IHC}$ in this study.
A

$\mathrm{kDa}$

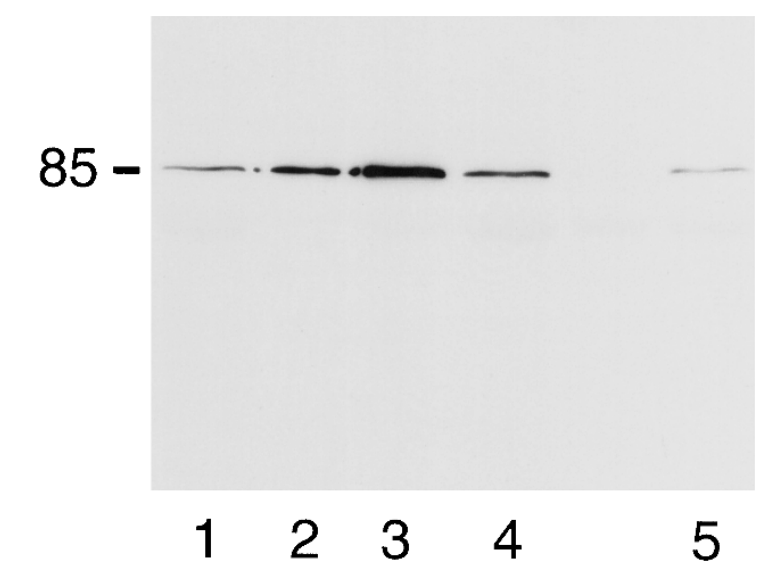

B

\section{$\mathrm{kDa}$}

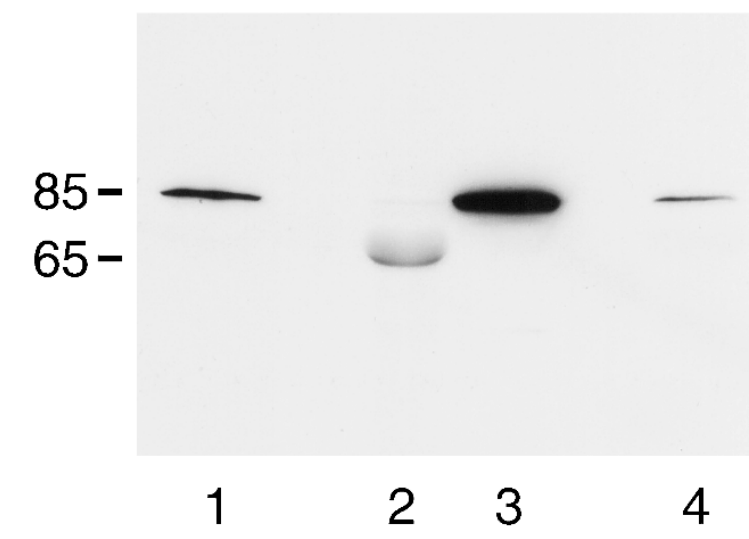

Figure 1.

Immunoblots for transglutaminase in carotid and coronary artery plaques. Carotid artery plaque was obtained at the time of carotid endarterectomy and coronary artery tissue was obtained by Directional Coronary Atherectomy. Protein homogenates were prepared and $25 \mu \mathrm{g}$ of total protein was separated by $10 \%$ SDS-PAGE as described in the "Materials and Methods" section. Immunoblotting was performed using an antibody to tissue transglutaminase (TG), CUB 7402. A, The immunoblot of four carotid plaques (lanes 1 to 4 ) and the homogenate of a normal internal mammary artery (lane 5). B, The immunoblot of three coronary atherectomy homogenates (lanes 1 to 3 ) and the internal mammary control (lane 4). TG antigen was detected in all cases at 85 $\mathrm{kd}$, as expected, except for one sample (B, lane 2), where a $65-\mathrm{kd}$ band, probably representing a proteolyzed sample, was seen.

\section{TG Antigen Localization}

TG was often detected in the fibrous cap overlying the necrotic core of a lipid-laden plaque, with TG antigen also present at the shoulders of the plaque. Figure 3 shows an example of a plaque obtained from a carotid endarterectomy that demonstrates these features. The fibrous cap, shown between the two arrows, contains TG antigen, which is especially prominent directly above the atheroma. TG antigen is also seen in the medium of the artery below the atheroma.

Figure 4 is a photomicrograph of TG and its product, $\epsilon(\gamma$-glutamyl)lysine isopeptide ("isopeptide"), in a 

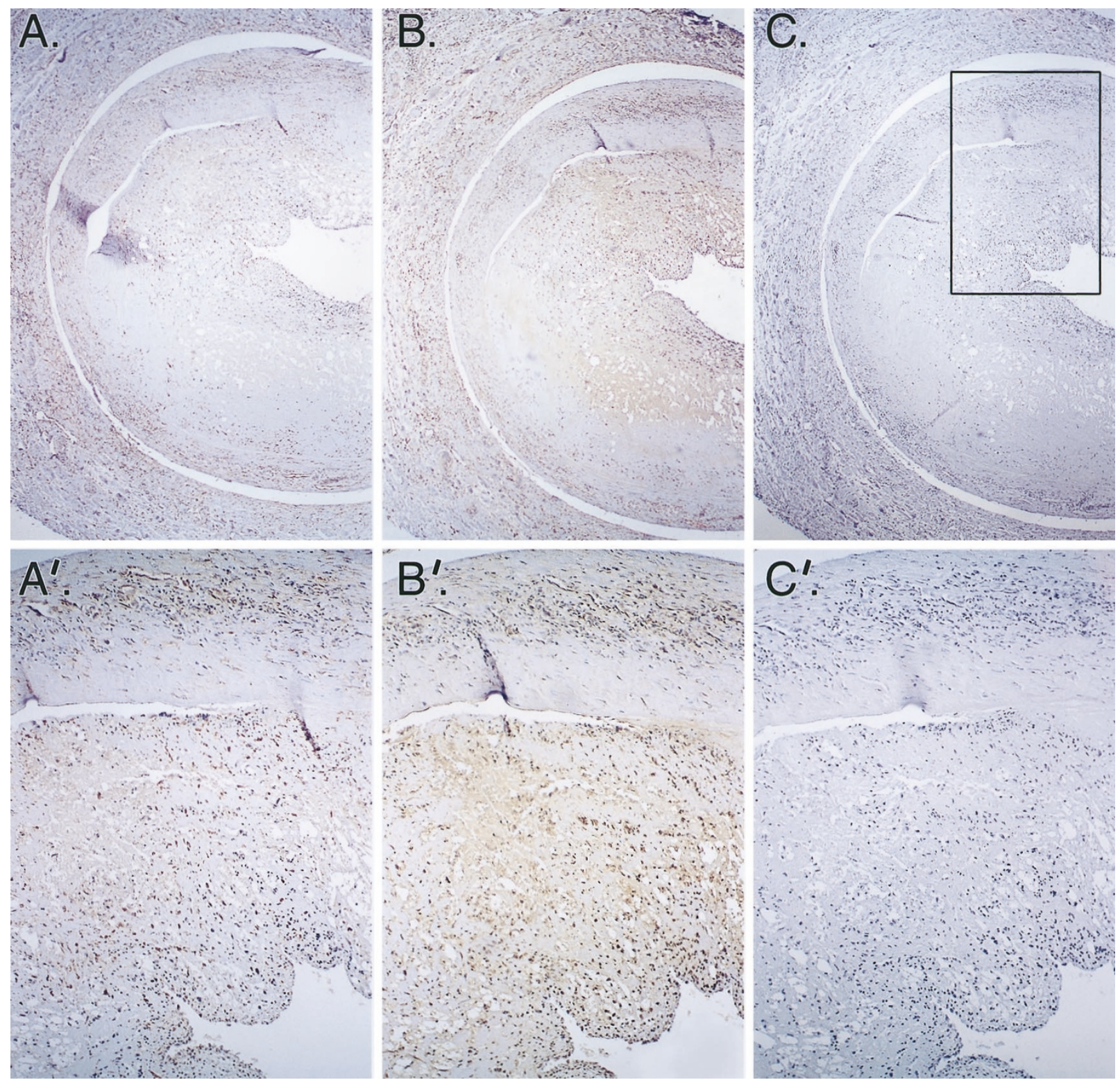

\section{Figure 2.}

Specificity of antibody to transglutaminase and activity product (isopeptide). A cross section of an atherosclerotic coronary artery plaque is shown. Immunohistochemistry (IHC) for TG antigen (A) and the distribution of the isopeptide (B) are shown. C, Control for the specificity of the IHC, normal mouse serum was used in place of the primary antibody. The rectangular region of interest in $C$ is shown at higher magnification in $C^{\prime}$. Similar regions from $A$ and $B$ are shown enlarged as $A^{\prime}$ and $B^{\prime}$, respectively. This figure demonstrates that $T G$ antigen and its isopeptide occur in similar distributions and that there is virtually no background reactivity under the conditions used for IHC in this study.

coronary artery plaque. TG antigen was prominent in the endothelium, within the intima, and in the medium of the vessel. The isopeptide was detected in a similar distribution to TG antigen (Fig. 4B). The TG distribution within the intima and the medium mirrored the distribution of SMC (Fig. 4C).

TG antigen was often detected in microvessels in both the intima (Fig. 5A) and the adventitia (Fig. 5C). No TG was detected in the adventitia, except in adventitial microvessels. Figure $5 \mathrm{C}$ also demonstrates the prominent immunoreactivity of the medium for the $\mathrm{TG}$ antigen.

A summary of all cases is presented in Table 1. The arterial medium was prominently immunoreactive for TG in all cases. The intima, plaque cap, and neovasculature exhibited variable intensities of TG immunoreactivity.

\section{TG Activity}

A standard activity assay was created using GPTG as a control (Fig. 6). The assay was linear between 0 and $1 \mu \mathrm{g} / \mathrm{ml}$. TG activity was assayed in the homogenized coronary atherectomy tissue of 14 patients (Table 2). Eight of the patients had no detectable activity. The remaining six patients had activity equivalent to 0.223 to $0.669 \mu \mathrm{g} / \mathrm{ml}$ of GPTG in 50 to $100 \mu \mathrm{g}$ of total protein. 


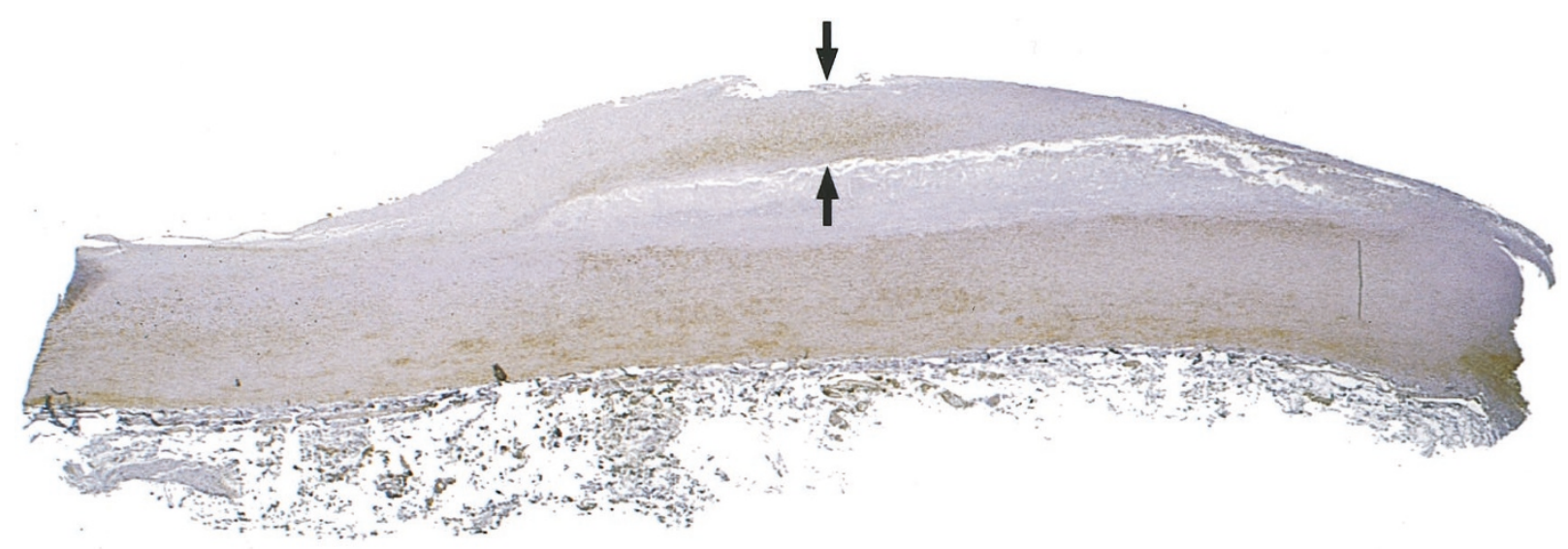

L

\section{$1.4 \mathrm{~cm}$}

Figure 3.

IHC studies of a carotid artery plaque. A longitudinal section of a carotid artery plaque from a 65 -year-old patient undergoing endarterectomy is shown after IHC for transglutaminase. The fibrous cap overlying a plaque is shown between the two arrows. TG antigen can be detected in the fibrous cap, as well as in the "shoulder regions" of the plaque. However, virtually no TG antigen can be seen inside the atheroma itself. TG antigen is also present in the medium of the vessel below the atheroma.

\section{Discussion}

In arteries with minimal or no atherosclerosis, transglutaminase antigen was detected exclusively in the medium and along the luminal endothelial border. In atherosclerotic arteries, TG antigen was detected at these sites as well as in the intima, within the fibrous cap, and in the endothelium of microvessels. In both normal and atherosclerotic arteries, the distribution of TG mirrored that of endothelial cells and SMC. The presence of TG in the fibrous cap and at the shoulder regions of atherosclerotic plaques could be effective in stabilizing the artery at these sites, rendering it less prone to rupture. The presence of transglutaminase on the luminal endothelium may prevent the dislodgment or erosion of endothelial cells that leads to coronary thrombosis without anatomical evidence of plaque rupture (Arbustini et al, 1999; Davies, 1997). The microvascular endothelial transglutaminase, on the other hand, could prevent the increased permeability and intra-plaque hemorrhage that often accompanies these vessels and that may predispose them to plaque rupture (Barger and Beeuwkes, 1990; McCarthy et al, 1999; Paterson, 1938; Zhang et al, 1993). All of the samples analyzed by immunohistochemistry showed similar anatomical distributions of TG antigen and isopeptide (Table 1). Our finding that 8 of 14 coronary atherectomy samples had no detectable TG activity (Table 2) could be a result of oxidant injury, nitrosylation (Melino et al, 1997), proteolysis, or the presence of histamine or other inhibitory substances in the plaque.

The mechanical and proteolytic forces that enhance atherosclerotic plaque rupture have been well characterized (Davies, 1996; Falk 1992; Lee and Kamm 1994; Lee and Libby, 1997; Loree et al, 1992; Richardson et al, 1989; Shah, 1997). TIMP enhance plaque stability by preventing the degradation of the collagen and elastin components of the ECM (Dellery et al, 1995). TG could provide a mechanism for the direct stabilization of atherosclerotic plaque against chemical, proteolytic, and physical disruptions (Greenberg et al, 1991). The $\epsilon(\gamma$-glutamyl)lysine isopeptide bond that is catalyzed by TG is particularly stable, even resisting degradation by lysosomal enzymes (Fesus et al, 1991). A variety of ECM components, including many that are expressed in the atheromatous plaque, are substrates for the transglutaminases. In particular, collagens type I and III, the major constituents of the fibrous cap (Libby et al, 1998; Rekhter et al, 1993), are cross-linked to fibronectin by TG (Mosher, 1984). Other types of collagen, including types II and V, are also substrates (Mosher, 1984). Entactin, a ubiquitous component of the basement membrane, is a substrate (Wu and Chung, 1991) that could be cross-linked by TG. This could potentially result in a more resilient barrier at the blood-vessel interface. Other substrates, such as vitronectin (Sane et al, 1990), osteopontin (Prince et al, 1991), thrombospondin (Bale and Mosher 1986), fibronectin (Martinez et al, 1994), dermatan sulfate proteoglycan (Kinsella and Wight, 1990), and apo(a) (Borth et al, 1991), are often increased in the atheromatous plaque (Dufourcq et al, 1998; Giachelli et al, 1995; Hajjar and Nachman, 1996; Riessen et al, 1994; Shekhonin et al, 1987; Wight et al, 1985).

In addition to directly cross-linking these matrix components, TG could also provide plaque stability by attaching protease inhibitors to specific plaque proteins. For example, $\alpha 2$-antiplasmin is cross-linked to the $\alpha$ chain of fibrinogen (Greenberg et al, 1987), and elafin, an inhibitor of elastase, is cross-linked to a variety of matrix proteins (Schalkwijk et al, 1999). The covalent bonding of these protease inhibitors to the 

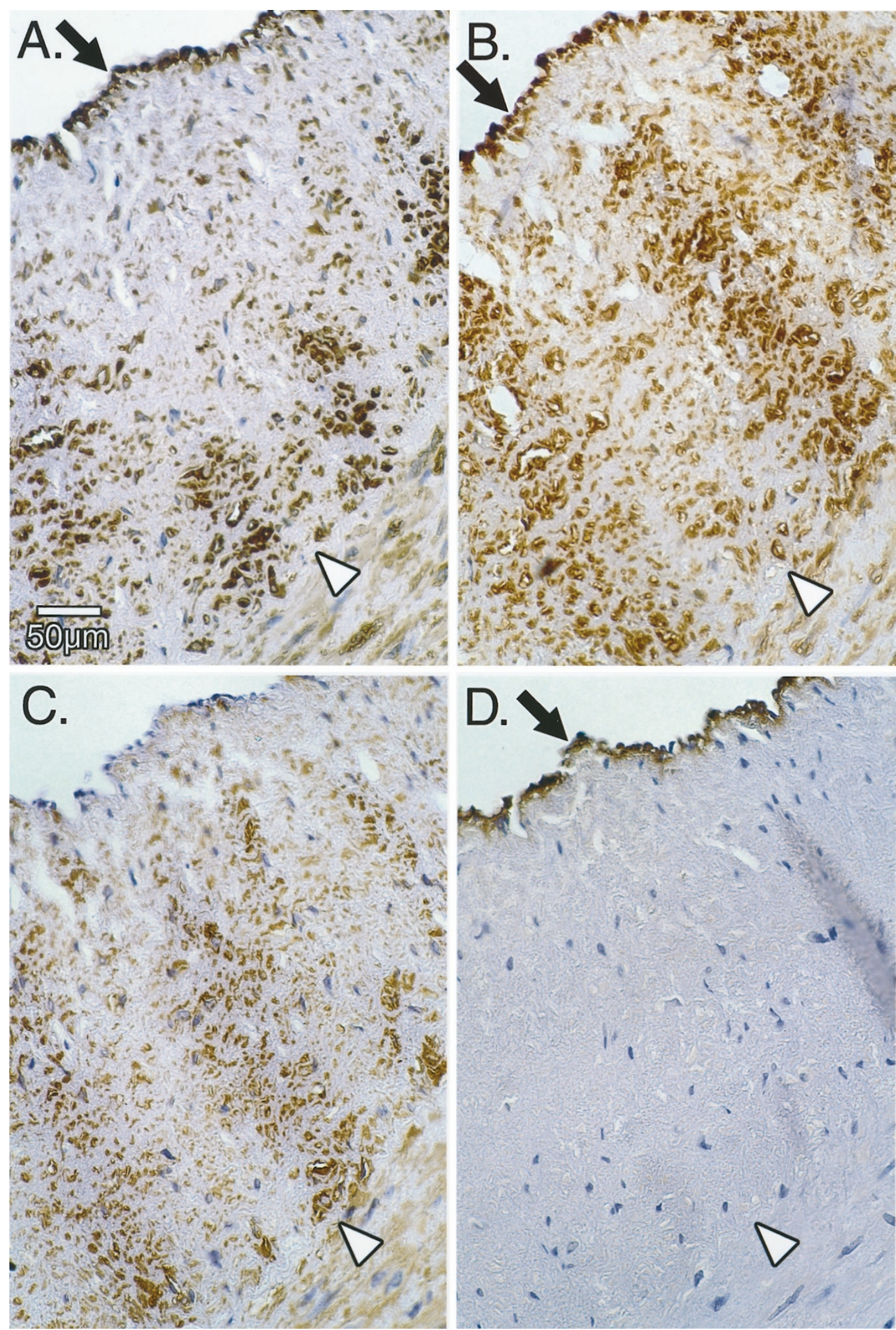

Figure 4.

Transglutaminase is found in endothelium and smooth muscle cells (SMC) and co-localizes with isopeptide. The proximal left anterior descending coronary artery was excised from the explanted heart of a 45-year-old male undergoing transplantation for ischemic cardiomyopathy. The artery was fixed in neutral buffered formalin, paraffin-embedded, and processed for IHC. A, Distribution of TG antigen, which is similar to that of the isopeptide (B). C, Distribution of SMC (detected with anti-SMC $\alpha$ actin) and $\mathrm{D}$, distribution of the luminal endothelium (detected with anti-von Willebrand factor). TG antigen was strongly immunoreactive along the luminal endothelial border (shown by the black arrows), throughout the intima, and in the medium of the vessel. The detection of TG antigen in the intima and medium of the vessel is similar to the distribution of SMC. The internal elastic lamina is indicated in all figures by the white arrowheads. Original magnification, $\times 400$. 

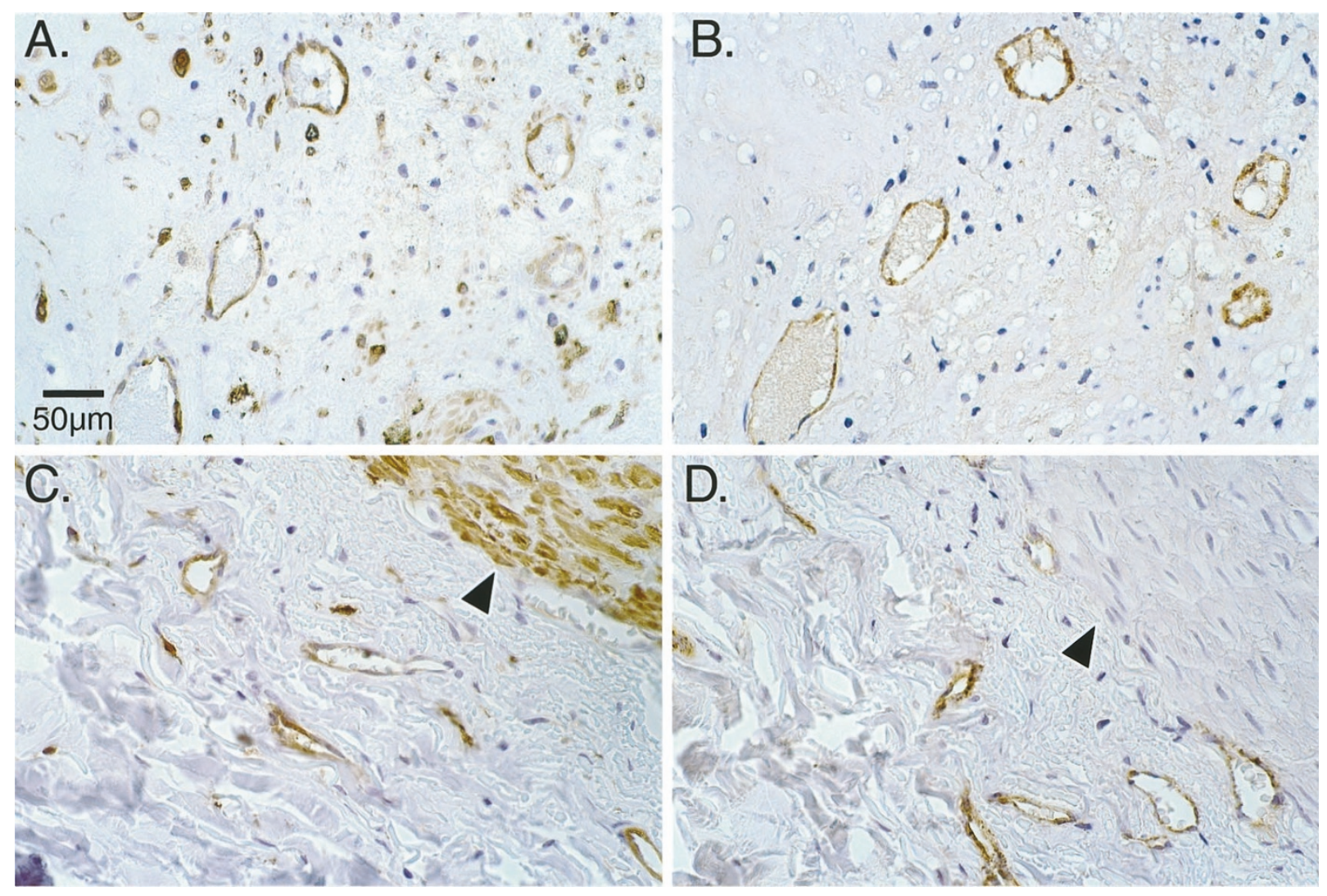

Figure 5.

Transglutaminase is detected in intimal and adventitial microvessels of an atherosclerotic coronary artery. TG antigen was often detected in microvessels, as demonstrated in these photomicrographs. A. Presence of TG antigen in intimal microvascular endothelial cells (as well as some other cells) is shown. B, Immunoreactivity for von Willebrand factor to identify the endothelial cells in a section adjacent to that shown in A. C and D, The medial-adventitial border. The external elastic lamina is identified by the black arrowheads. TG antigen (C) is present in the microvascular endothelium and in the SMC that are present in the medium (upper right-hand corner). Endothelial cells were identified using an antibody to von Willebrand factor (D). Original magnification, $\times 400$.

Table 1. Tissue Transglutaminase in Coronary and Carotid Atherosclerosis

\begin{tabular}{|c|c|c|c|c|c|c|}
\hline Age & Vessel & Luminal Stenosis & Medium & Intima & Plaque Cap & Neovasculature \\
\hline \multicolumn{7}{|c|}{ Coronary Arteries } \\
\hline 23 & LAD & negligible & +++ & - & N.A. & N.A. \\
\hline 41 & LAD & $50 \%$ & +++ & +++ & ++ & +++ \\
\hline 45 & LAD & $90 \%$ & ++ & +++ & N.A. & +++ \\
\hline 57 & $\mathrm{RCA}$ & $10 \%$ & +++ & - & N.A. & N.A. \\
\hline 59 & $\mathrm{LAD}$ & $75 \%$ & +++ & ++ & + & N.A. \\
\hline 66 & LAD & $50 \%$ & +++ & + & N.A. & + \\
\hline 68 & LAD & $90 \%$ & ++ & +++ & ++ & +++ \\
\hline \multicolumn{7}{|c|}{ Carotid Arteries } \\
\hline 65 & $\mathrm{RIC}$ & $75 \%$ & +++ & ++ & ++ & + \\
\hline 68 & LIC & $75 \%$ & ++ & ++ & + & N.A. \\
\hline 72 & LIC & $60 \%$ & +++ & ++ & N.A. & + \\
\hline 74 & RIC & $60 \%$ & +++ & ++ & +++ & +++ \\
\hline 75 & $\mathrm{RIC}$ & $75 \%$ & ++ & ++ & ++ & +++ \\
\hline 78 & LIC & $75 \%$ & +++ & ++ & ++ & ++ \\
\hline 78 & LIC & $60 \%$ & ++ & ++ & N.A. & ++ \\
\hline
\end{tabular}

LAD, left anterior descending coronary artery; RCA, right coronary artery; RIC, right internal carotid; LIC, left internal carotid; N.A., not applicable (plaque cap or neovasculature not visualized on sections)

The isopeptide was localized in all sections in a similar distribution to that of TG antigen.

plaque matrix could prevent plasmin-mediated activation of MMP and elastin degradation by elastase.

TG could also indirectly stabilize the plaque by activating latent transforming growth factor-beta-1
(TGF- $\beta 1$ ) (Kojima et al, 1993). TGF- $\beta 1$ is secreted in an inactive complex comprised of latent TGF- $\beta 1$ and the latency associated peptide. TG-mediated activation of TGF- $\beta 1$ requires cross-linking of latency associated 


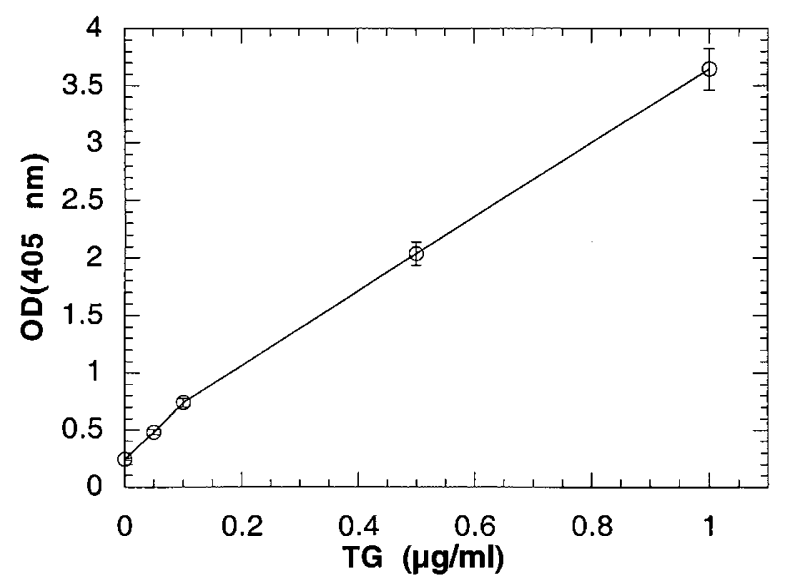

Figure 6.

TG activity standard curve. A colorimetric assay for transglutaminase was established, using guinea pig liver transglutaminase (GPTG) as the standard enzyme. The assay is based on the incorporation of 5-biotinamindopentylamine into immobilized N, N'-dimethylcasein, as described in "Materials and Methods." The assay was linear between 0 and $1 \mu \mathrm{g} / \mathrm{ml}$ of GPTG. This assay was used to determine the activity of transglutaminase in coronary artery atherectomy tissue (Table 2).

peptide to components of the ECM (Kojima et al, 1993; Nunes et al, 1995, 1997). Once activated, TGF- $\beta 1$ enhances the expression of a variety of ECM components and induces inhibitors of matrix degradation (plasminogen activator inhibitor type 1 [PAl-1] and TIMP). TGF- $\beta 1$ also inhibits the expression of matrix degrading enzymes (plasminogen activators and MMP) (Massagué, 1990). Thus, increased TGF- $\beta 1$ activity, mediated by TG activation of the latent complex, could strengthen the plaque against rupture. The increased ECM content could also promote plaque progression.

In addition to its ability to stabilize the plaque by cross-linking important ECM substrates, TG has other roles that could affect the stability of the atheromatous plaque and its response to injury. These include a direct cell adhesive action (Gentile et al, 1992), roles in apoptosis (Fesus et al, 1989, 1991), the regulation of cell growth (Birckbichler and Patterson, 1978), and wound healing (Bowness et al, 1988). TG in the intracellular compartment also has a recently recognized role as a $\mathrm{G}$ protein in signal transduction (Nakaoka et al, 1994). Thus, transglutaminase is able to alter many of the processes that are thought to regulate plaque stability (Davies, 1996; Falk, 1992; Lee and Kamm, 1994; Lee and Libby, 1997; Loree et al, 1992; Richardson et al, 1989; Shah 1997), and it may have other roles that are important to endothelial and SMC functions.

A variety of factors could affect the activity of TG in the plaque. TG is sensitive to oxidant stress, presumably through oxidant modification of an active-site cysteine (residue 276) (Greenberg et al, 1991). TG has 16 additional free cysteine residues that are potential targets for oxidation (Folk, 1983). The water-soluble gas phase extracts of cigarette smoke, in concentrations as low as $0.5 \%$, can inhibit the TG content of $10^{7}$ human alveolar macrophages by $40 \%$ (Roth et al,
1986). Nitric oxide can inhibit transglutaminase activity through nitrosylation of the active-site cysteine (Bernassola et al, 1999; Catani et al, 1998; Melino et al, 1997) or through the reaction of nitric oxide with $\mathrm{O}_{2}$ to form peroxynitrite, because cysteine residues are particularly sensitive to oxidation with peroxynitrite (Berlett and Stadtman, 1997). Thus, the generation of oxidant stress from smoking (Pryor et al, 1984; Tully et al, 1969), hyperlipidemia (Ohara et al, 1993), diabetes (Horie et al, 1997; Schmidt et al, 1995), and hypertension (Harrison, 1997; Scheidegger et al, 1997), as well as the health status of the endothelium, which is influenced by these and other risk factors (Harrison, 1997), could modulate TG activity.

The content of glycosaminoglycans could also modulate the ability of TG to form plaque-stabilizing protein cross-links. Both midkine (Kojima et al, 1997) and vitronectin (Sane et al, 1990) are much more readily cross-linked by $\mathrm{TG}$ in the presence of sulfaterich glycosaminoglycans. Interestingly, the content of sulfated glycosaminoglycans is reduced in the cap of the unstable plaque (Davies et al, 1994).

Another influence on TG activity could be the presence of amine compounds that are known to competitively inhibit the enzyme (Ishitani and Suzuki, 1989; Martinez et al, 1989; Stenberg et al, 1975). Degranulating mast cells, which release histamine, an inhibitor of TG (Martinez et al, 1989), are a component of the cellular inflammatory response in the plaque (Kaartinen et al, 1998; Kovanen et al, 1995; Lendon et al, 1991, van der Wal et al, 1994). Recently, it was shown that the mast cell content of unstable plaques is increased compared with stable plaques (Kaartinen et al, 1998). Histamine is released from mast cells during myocardial ischemia (Frangogiannis et al, 1998) and is found in significantly higher levels (two-fold increase) in coronary arteries from patients who died from coronary heart disease compared with controls (Kalsner and Richards, 1984).

In summary, TG is present in the atherosclerotic plaques of coronary and carotid arteries. Although the enzyme is active in at least some plaques, a variety of factors that are involved in the pathogenesis of atherosclerosis could inhibit its activity. The inhibition of TG at anatomically critical sites, such as the "shoulder" region of the plaque could contribute to plaque rupture.

\section{Materials and Methods}

The monoclonal antibody to GPTG, CUB 7402, was a gift from Dr. Paul J. Birckbichler (Birckbichler et al, 1985), Oklahoma Medical Research Foundation, Oklahoma City, Oklahoma, and was also purchased (NeoMarkers, Lab Vision Corporation, Fremont, California). CUB 7402 cross-reacts with TG from a variety of species, including human (Greenberg et al, 1987). Another antibody to TG, TG100, was also obtained from this source. Combinations of TG100 and CUB 7402 (MS-300; NeoMarkers, Lab Vision Corporation) were also used for immunoblotting. The previously characterized $\operatorname{lgM} \kappa$ murine monoclonal antibody to the $\mathrm{N} \epsilon(\gamma$-glutamyl)lysine isopeptide, 
Table 2. Transglutaminase Activity in Coronary Artery Atherectomy Tissue

\begin{tabular}{ccccccc}
\hline $\begin{array}{r}\text { Patient } \\
\text { Number }\end{array}$ & Age & Sex & Target Vessel & ACIS Type & $\begin{array}{c}\text { TP Analyzed } \\
(\mu \mathrm{g})\end{array}$ & $\begin{array}{c}\text { Equivalent } \\
\text { GPTG Activity } \\
(\mu \mathrm{g} / \mathrm{ml})\end{array}$ \\
\hline 1 & 70 & $\mathrm{M}$ & LAD & UAP & 100 & N.D. \\
2 & 87 & $\mathrm{~F}$ & RCA & UAP & 80 & N.D. \\
3 & 73 & F & RCA & UAP & 100 & 0.641 \\
4 & 63 & M & CIRC & Ml & 100 & N.D. \\
5 & 45 & M & RCA & UAP & 50 & N.D. \\
6 & 70 & M & RCA & Ml & 50 & N.D. \\
7 & 66 & F & LAD & Ml & 50 & 0.395 \\
8 & 48 & M & CIRC & UAP & 100 & 0.288 \\
9 & 87 & M & LAD & Ml & 50 & 0.243 \\
10 & 51 & M & LAD & Ml & 80 & 0.223 \\
11 & 61 & M & RCA & Ml & 80 & 0.669 \\
12 & 64 & F & RCA & Ml & 80 & N.D. \\
13 & 44 & M & RCA & Ml & 80 & N.D. \\
14 & 65 & F & RCA & UAP & 80 & N.D. \\
\hline
\end{tabular}

RCA, right coronary artery; CIRC, circumflex coronary artery; LAD, left anterior descending coronary artery; ACIS, acute coronary ischemic syndrome; UAP, unstable angina pectoris; MI, myocardial infarction; TP, total protein; GPTG, guinea pig liver transglutaminase; N.D., no detectable activity.

814 MAM (Roem et al, 1991), was obtained from CovalAb Oullins (Cedex, France). A murine monoclonal antibody to smooth muscle actin, clone $1 \mathrm{~A} 4$, was purchased from DAKO (Carpinteria, California) and a rabbit polyclonal antibody to von Willebrand's factor, RB281-P, was purchased from NeoMarkers, Lab Vision Corporation. GPTG was purchased from Sigma Chemical (St. Louis, Missouri); N, N'-dimethylcasein from Calbiochem (San Diego, California), and 5-biotinamidopentylamine from Pierce Chemical Company (Indianapolis, Indiana). Alkaline phosphatase substrate was purchased from BioRad (Richmond, California). Chemiluminescence reagents (SuperSignal) were purchased from Pierce Chemical Company (Indianapolis, Indiana).

\section{IHC}

IHC was performed using procedures described by Sternberger et al (1970) and Hsu et al (1981). Briefly, paraffin embedded tissues were sectioned (5-microns thick) and antigen retrieval was performed using citrate buffer (Biogenex, San Ramon, California). Tissues were treated with the primary antibodies described above. To control for non-specific binding, normal mouse serum was substituted for the primary antibody on some sections. Secondary and tertiary antibodies were provided in a kit (314 KLD; Innovex, Richmond, California) and the reaction was visualized with 3,3'-diaminobenzidine tetrahydrochloride (Sigma). Slides were counterstained with hematoxylin (Sigma).

\section{Tissue Specimens}

Coronary artery sections were obtained from autopsies and from the explanted hearts of patients undergoing heart transplants at North Carolina Baptist Hospital and from the Cooperative Human Tissue Network of the National Cancer Institute. Sections of coronary arteries from seven patients (five from autopsies, two from explanted hearts of patients undergoing heart transplant), ages 23 to 88 years old, with varying extents of coronary artery disease, ranging from negligible to severe were processed for IHC against TG. Four of the patients were male and three were female. Coronary artery tissue was obtained from 17 patients, ages 44 to 87 , undergoing Directional Coronary Atherectomy. Fourteen of these samples were used for TG activity assays and three were used to prepare homogenates for immunoblotting. Carotid artery tissue was obtained at the time of endarterectomy from 11 patients, ages 65 to 79 years old. Sections of seven of these carotid arteries were used for $\mathrm{IHC}$ and four were used to prepare protein homogenates for immunoblotting. A segment of a left internal mammary artery that was trimmed at the time of bypass grafting was obtained and a protein homogenate was prepared for use as a normal control with immunoblotting. Tissue procurement was approved by the Institutional Review Board (IRB).

\section{Immunoblotting}

All fat was removed from the internal mammary artery using a dissecting microscope. Control artery, carotid endarterectomy plaque, and coronary atherectomy tissue were rinsed in ice-cold Tris-buffered saline (150 $\mathrm{mm} \mathrm{NaCl}, 10 \mathrm{~mm}$ Tris, $\mathrm{pH}$ 7.4) and homogenized in Tris-buffered saline containing a protease inhibitor cocktail for general use (P2714; Sigma Chemical). Particulate debris was removed by centrifuging at $10,000 \times g$ for 10 minutes. The protein concentration of the supernatant was determined using the BioRad protein assay. Twenty-five micrograms of protein was mixed with sample buffer (5\% 2-mercaptoethanol, 1\% sodium dodecyl sulfate, $1.5 \mathrm{M}$ urea, $2.5 \mathrm{~mm}$ EDTA, 30 $\mathrm{mm}$ Tris- $\mathrm{HCl} \mathrm{pH} 7.5$, and $0.001 \%$ bromphenol blue), 
then subjected to SDS-PAGE on a 10\% Laemmli gel. Immunoblotting was performed using a 1:1000 dilution of TG antibody followed by an anti-mouse IgG conjugated to horseradish peroxidase at a dilution of 1:5000. Bound antibodies were detected with chemiluminescence (SuperSignal, Piece Chemical Company).

\section{Coronary Artery Transglutaminase Activity Assay}

Coronary artery atherectomy samples were frozen in liquid nitrogen immediately after retrieval from the patient, then pulverized and lysed in $10 \mathrm{~mm}$ Tris- $\mathrm{HCl}$, $\mathrm{pH} 7.5$, containing $1 \mathrm{~mm} \mathrm{MgCl}_{2}, 1 \mathrm{~mm}$ EGTA, $5 \mathrm{~mm}$ $\beta$-mercaptoethanol, $0.5 \%$ CHAPS, $0.1 \mathrm{~mm}$ AEBSF, and $10 \%$ glycerol. The lysates were centrifuged at $16,000 \times \mathrm{g}$ for 30 minutes at $4^{\circ} \mathrm{C}$, and the supernatant was used in an ELISA-based assay for transglutaminase, as previously described (Slaughter et al, 1992), with minimal modifications. This assay is based on the incorporation of the TG substrate 5-biotinamidopentylamine (5-BPA; Pierce Chemical Company) into immobilized $\mathrm{N}, \mathrm{N}^{\prime}$-dimethylcasein, with subsequent detection using streptavidin-alkaline phosphatase. Homogenates of coronary artery atherectomy tissue (50 to $100 \mu \mathrm{g}$ ) were added to reaction buffer $(100 \mu$ l of $0.1 \mathrm{M}$ Tris- $\mathrm{HCl} \mathrm{pH} 8.5,10 \mathrm{~mm}$ 5-BPA, and $10 \mathrm{~mm}$ dithiothreitol), and added to each well of an ELISA plate that had been coated with $\mathrm{N}$, $\mathrm{N}^{\prime}$-dimethylcasein and blocked with BSA as described (Slaughter et al, 1992). Control for nonspecific binding was performed by omitting 5-BPA. The homogenized atherectomy samples were incubated with the immobilized $\mathrm{N}, \mathrm{N}^{\prime}$-dimethylcasein for 1 hour and the plate was washed as described (Slaughter et al, 1992). To each well, $100 \mu \mathrm{l}$ of a 1:500 dilution of streptavidin-alkaline phosphatase solution in $100 \mathrm{~mm}$ Tris $\mathrm{pH} 8.5,150 \mathrm{~mm} \mathrm{NaCl}, 0.05 \%$ Tween-20, and 1\% BSA was added for 1 hour at room temperature. After washing, color was developed using p-nitrophenylphosphate in diethanolamine buffer (BioRad). Purified TG (Sigma Chemical) was used to establish a standard curve.

\section{References}

Arbustini E, Dal Bello P, Morbini P, Burke AP, Bocciarelli M, Specchia G, and Virmani R (1999). Plaque erosion is a major substrate for coronary thrombosis in acute myocardial infarction. Heart 82:269-272.

Bale MD and Mosher DF (1986). Thrombospondin is a substrate for blood coagulation factor XIIla. Biochemistry 25:5667-5673.

Barger AC and Beeuwkes R (1990). Rupture of coronary vasa vasorum as a trigger of acute myocardial infarction. Am J Cardiol 66:41G-43G.

Berlett BS and Stadtman ER (1997). Protein oxidation in aging, disease, and oxidative stress. J Biol Chem 272:2031320316.

Bernassola F, Rossi A, and Melino G (1999). Regulation of transglutaminases by nitric oxide. Ann NY Acad Sci 887:8391.
Birckbichler PJ and Patterson MK Jr (1978). Cellular transglutaminase, growth and transformation. Annals NY Acad Sci 312:354-365.

Birckbichler PJ, Upchurch HF, Patterson MK Jr, and Conway E (1985). A monoclonal antibody to cellular transglutaminase. Hybridoma 4:179-186.

Borth W, Chang V, Bishop P, and Harpel PC (1991). Lipoprotein (a) is a substrate for factor XIIla and tissue transglutaminase. J Biol Chem 266:18149-18153.

Bowness JM, Tarr AH, and Wong T (1988). Increased transglutaminase activity during skin wound healing in rats. Biochim Biophys Acta 967:234-240.

Catani MV, Bernassola F, Rossi A, and Melino G (1998). Inhibition of clotting factor XIII activity by nitric oxide. Biochem Biophys Res Commun 249:275-278.

Davies MJ (1996). Stability and instability: The two faces of coronary atherosclerosis. Paul Dudley White Lecture 1995. Circulation 94:2013-2020.

Davies MJ (1997). The composition of coronary artery plaques. N Engl J Med 336:1312-1314.

Davies MJ, Woolf N, Rowles P, and Richardson PD (1994). Lipid and cellular constituents of unstable human aortic plaques. Basic Res Cardiol 89(Suppl 1):33-39.

Dellery CM, McEwan JR, and Henney AM (1995). Matrix metalloproteinases and cardiovascular disease. Circ Res 77:863-868.

Dufourcq P, Louis H, Moreau C, Daret D, Boisseau MR, Lamaziere JM, and Bonnet J (1998). Vitronectin expression and interaction with receptors in smooth muscle cells from human atheromatous plaque. Arterioscler Thromb Vasc Biol 18:168-176.

Falk E (1992). Progressive atherogenesis: Why do plaques rupture? Circulation 86(Suppl III):30-42.

Fesus L, Tarcsa E, Kedei N, Autuori F, and Piacentini M (1991). Degradation of cells dying by apoptosis leads to accumulation of $\epsilon(\gamma$-glutamyl)lysine isodipeptide in culture fluid and blood. FEBS Lett 284:109-112.

Fesus L, Thomazy V, Autori F, Ceru MP, Tarcsa E, and Piacentini M (1989). Apoptotic hepatocytes become insoluble in detergents and chaotropic agents as a result of transglutaminase action. FEBS Lett 245:150-154.

Folk JE (1983). Mechanism and basis for specificity of transglutaminase-catalyzed $\epsilon$-( $\gamma$-glutamyl)lysine bond formation. Adv Enzymol Relat Areas Mol Biol 54:1-56.

Frangogiannis NG, Lindsey ML, Michael LH, Youker KA, Bressler RB, Mendoza LH, Spengler RN, Smith CW, and Entman ML (1998). Resident cardiac mast cells degranulate and release preformed TNF-alpha, initiating the cytokine cascade in experimental myocardial ischemia/reperfusion. Circulation 98:699-710.

Galis Z, Sukhova G, Lark M, and Libby P (1994). Increased expression of matrix metalloproteinases and matrix degrading activity in vulnerable regions of human atherosclerotic plaques. J Clin Invest 94:2493-2503.

Geng YJ and Libby P (1995). Evidence for apoptosis in advanced human atheroma. Colocalization with interleukin-1 beta-converting enzyme. Am J Pathol 147:251-266. 
Gentile V, Saydak M, Chiocca EA, Akande O, Birckbichler PJ, Lee KN, Stein JP, and Davies PJ (1991). Isolation and characterization of cDNA clones to mouse macrophage and human endothelial cell tissue transglutaminases. J Biol Chem 266:478-483.

Gentile V, Thomazy V, Piacentini M, Fesus L, and Davies PJ (1992). Expression of tissue transglutaminase in BALB-C 3T3 fibroblasts: Effects on cellular morphology and adhesion. J Cell Biol 119:463-474.

Giachelli CM, Liaw L, Murry CE, Schwartz SM, and Almeida $M$ (1995). Osteopontin expression in cardiovascular diseases. Annal NY Acad Sci 760:109-126.

Greenberg CS, Achyuthan KE, Borowitz MJ, and Shuman MA (1987). The transglutaminase in vascular cells and tissues could provide an alternate pathway for fibrin stabilization. Blood 70:702-709.

Greenberg CS, Birckbichler PJ, and Rice RH (1991). Transglutaminases: Multifunctional cross-linking enzymes that stabilize tissues. FASEB J 5:3071-3077.

Hajjar KA and Nachman RL (1996). The role of lipoprotein (a) in atherogenesis and thrombosis. Annu Rev Med 47:423442 .

Harrison DG (1997). Endothelial function and oxidant stress. Clin Cardiol 20 (Suppl 2):11-17.

Horie K, Miyata T, Maeda K, Miyata S, Sugiyama S, Sakai H, Strihou CY, Monnier VM, Witzum JL, and Kurokawa K (1997). Immunohistochemical colocalization of glycoxidation products and lipid peroxidation products in diabetic renal glomerular lesions. Implication for glycoxidative stress in the pathogenesis of diabetic nephropathy. J Clin Invest 100:29953004.

Hsu S, Raine L, and Fanger H (1981). Use of avidin-biotin peroxidase complex $(A B C)$ in immunoperoxidase techniques: A comparison between $A B C$ unlabeled antibody (PAP) procedures. J Histochem Cytochem 29:577-580.

Ishitani K and Suzuki M (1989). Influence of transglutaminase on the functions of mouse peritoneal macrophages. Microbiol Immunol 33:59-68.

Kaartinen M, Van Der Wal AC, Van Der Loos CM, Piek JJ, Koch KT, Becker AE, and Kovanen PT (1998). Mast cell infiltration in acute coronary syndromes: Implications for plaque rupture. J Am Coll Cardiol 32:606-612.

Kalsner S and Richards R (1984). Coronary arteries of cardiac patients are hyperreactive and contain stores of amines: A mechanism for coronary spasm. Science 223:1435-1437.

Kinsella MG and Wight TN (1990). Formation of high molecular weight dermatan sulfate proteoglycan in bovine aortic endothelial cell cultures. Evidence for transglutaminasecatalyzed cross-linking to fibronectin. J Biol Chem 265: 17891-17898.

Kojima S, Inui T, Muramatsu H, Suzki Y, Kadomatsu K, Yoshizawa M, Hirose S, Kimura T, Sakakibara S, and Muramatsu T (1997). Dimerization of midkine by tissue transglutaminase and its functional implication. J Biol Chem 272: 9410-9416.

Kojima S, Nara K, and Rifkin DB (1993). Requirement for transglutaminase in the activation of latent transforming growth factor- $\beta$ in bovine endothelial cells. J Cell Biol 121: $439-448$.
Kovanen P, Kaartinen M, and Paavonen T (1995). Infiltrates of activated mast cells at the site of coronary atheromatous erosion or rupture in myocardial infarction. Circulation 92: 1084-1088.

Lee RT and Kamm RD (1994). Vascular mechanics for the cardiologist. J Am Coll Cardiol 23:1289-1295.

Lee RT and Libby P (1997). The unstable atheroma. Arterioscler Thromb Vasc Biol 17:1859-1867.

Lendon CL, Davies MJ, Born GV, and Richardson PD (1991). Atherosclerotic plaque caps are locally weakened when macrophage density is increased. Atherosclerosis 87:87-90.

Libby P, Ganz P, Schoen FJ, and Lee RT (1998). Vascular biology of the acute coronary syndromes. In: Topol EJ, editor. Acute coronary syndromes. New York: Marcel Dekker, $1-19$.

Loree HM, Kamm RD, Stringfellow RG, and Lee RT (1992). Effects of fibrous cap thickness on peak circumferential stress in model atherosclerotic vessels. Circ Res 71:850-858.

Martinez J, Chalupowicz DG, Roush RK, Sheth A, and Barsigian C (1994). Transglutaminase-mediated processing of fibronectin by endothelial cell monolayers. Biochemistry 33:2538-2545.

Martinez J, Rich E, and Barsigian C (1989). Transglutaminase-mediated cross-linking of fibrinogen by human umbilical vein endothelial cells. J Biol Chem 264: 20502-20508.

Massagué J (1990). The transforming growth factor- $\beta$ family. Annu Rev Cell Biol 6:597-641.

McCarthy MJ, Loftus IM, Thompson MM, Jones L, London NJM, Bell PRF, Naylor AR, and Brindle NPJ (1999). Angiogenesis and the atherosclerotic carotid plaque: An association between symptomatology and plaque morphology. $J$ Vasc Surg 30:261-268.

Melino G, Bernassola F, Knight RA, Corasaniti MT, Nistico G, and Finazzi-Agro A (1997). S-nitrosylation regulates apoptosis. Nature 388:432-433.

Mosher DF (1984). Cross-linking of fibronectin to collagenous proteins. Mol Cell Biochem 58:63-68.

Nakaoka H, Perez DM, Back KJ, Das T, Husain A, Misono K, Im MJ, and Graham RM (1994). Gh: A GTP-binding protein with transglutaminase activity and receptor signaling function. Science 264:1593-1596.

Nunes I, Gleizes PE, Metz CN, and Rifkin DB (1997). Latent transforming growth factor-beta binding protein domains involved in activation and transglutminase-dependent crosslinking of latent transforming growth factor-beta. J Cell Biol 136:1151-1163.

Nunes I, Shapiro RL, and Rifkin DB (1995). Characterization of latent TGF-beta activation by murine peritoneal macrophages. J Immunol 155:1450-1459.

Ohara Y, Peterson TE, and Harrison DG (1993). Hypercholesterolemia increases endothelial superoxide anion production. J Clin Invest 91:2546-2551.

Paterson JC (1938). Capillary rupture with intimal hemorrhage as a causative factor in coronary thrombosis. Arch Pathol 25:474-487.

Prince CW, Dickie D, and Krumdieck CL (1991). Osteopontin, a substrate for transglutaminase and factor XIII activity. Biochem Biophys Res Commun 177:1205-1210. 
Pryor WA, Dooley MM, and Church DF (1984). Inactivation of alpha-1-proteinase inhibitor by gas phase cigarettes smoke. Biochem Biohys Res Commun 122:676-681.

Rekhter MD, Zhang K, Narayanan AS, Phan S, Schork MA, and Gordon D (1993). Type I collagen gene expression in human atherosclerosis. Localization to specific plaque regions. Am J Pathol 143:1634-1648.

Richardson PD, Davies MJ, and Born GVR (1989). Influence of plaque configuration and stress distribution on fissuring of coronary atherosclerotic plaque. Lancet 2:941-944.

Riessen R, Isner JN, Blessing E, Loushin C, Nikol S, and Wight TN (1994). Regional differences in the distribution of biglycan and decorin in the extracellular matrix of atherosclerotic and restenotic human coronary arteries. Am J Pathol 144:962-974.

Roem A-M, Noel P, El Alaoui S, Charlot C, and Quash G (1991). Differential expression of isopeptide bonds $N \epsilon(\gamma$ glutamyl)lysine in benign and malignant human breast lesions: An immunohistochemical study. Int J Cancer 48: 215-220.

Romanic AM, Arleth AJ, Willette RN, and Ohlstein EH (1998). Factor XIIla cross-links lipoprotein (a) with fibrinogen and is present in human atherosclerotic lesions. Circ Res 83:264269.

Roth WJ, Chung SI, and Janoff A (1986). Inactivation of alveolar macrophage transglutaminase by oxidants in cigarette smoke. J Leukoc Biol 39:629-644.

Sane DC, Moser TL, Parker CJ, Seiffert D, Loskutoff DJ, and Greenberg CS (1990). Highly sulfated glycosaminoglycans augment the cross-linking of vitronectin by guinea pig liver transglutaminase. J Biol Chem 265:3543-3548.

Schalkwijk J, Wiedow O, and Hirose S (1999). The trappin gene family: Proteins defined by an N-terminal transglutaminase substrate domain and a C-terminal four-disulphide core. Biochem J 340:569-577.

Scheidegger KJ, Butler S, and Witzum JL (1997). Angiotensin II increases macrophage-mediated modification of low density lipoprotein via a lipoxygenase-dependent pathway. J Biol Chem 272:21609-21615.

Schmidt AM, Hori O, Chen JX, Li JF, Crandall J, Zhang J, Cao R, Yan SD, Brett J, and Stern D (1995). Advanced glycation end products interacting with their endothelial receptor induce expression of vascular cell adhesion molecule-1 (VCAM-1) in cultured human endothelial cells and in mice: A potential mechanism for the accelerated vasculopathy of diabetes. J Clin Invest 96:1395-1403.

Shah PK (1997). Plaque disruption and coronary thrombosis: New insights into pathogenesis and prevention. Clin Cardiol 20:II38-II44.
Shah PK, Falk E, Badimon JJ, Fernandez-Ortiz A, Mailhac A, Villareal-Levy G, Fallon JT, Regnstrom J, and Fuster V (1995). Human monocyte-derived macrophages induce collagen breakdown in fibrous caps of atherosclerotic plaques: Potential role of matrix degrading metalloproteinases and implications for plaque rupture. Circulation 92:1565-1569.

Shainoff JR and Page IH (1972). Deposition of modified fibrinogen within the aortic intima. Atherosclerosis 16:287305.

Shekhonin BV, Domogatsky SP, Idelson GL, Koteliansky VE, and Rukosuev VS (1987). Relative distribution of fibronectin and type I, III, IV, V collagens in normal and atherosclerotic intima of human arteries. Atherosclerosis 676:9-16.

Slaughter TF, Achyuthan KE, Lai TS, and Greenberg CS (1992). A microtiter plate transglutaminase assay utilizing 5-(biotinamido)pentylamine as substrate. Anal Biochem 205: 166-171.

Stenberg P, Curtis CG, Wing D, Tong YS, Credo RB, Gray A, and Lorand $L$ (1975). Transamidase kinetics. Amide formation in the enzymic reactions of thiol esters with amines. Biochem J 147:153-163.

Sternberger LA, Hardy PH Jr, Cuculis JJ, and Meyer HG (1970). The unlabeled antibody enzyme method of immunohistochemistry: Preparation and properties of soluble antigen-antibody (horseradish peroxidase-antihorseradish peroxidase) and its use in identification of spirochetes. $\mathrm{J}$ Histochem Cytochem 18:315.

Tully G, Briggs C, and Horsfield A (1969). EPR adsorption by the vapor phase of cigarette smoke, condensed and examined at low temperatures. Chem Ind 7:201-203.

Valenzuela R, Shainoff JR, DiBello PM, Urbanic DA, Anderson JM, Matsueda GR, and Kudryk BJ (1992). Immunoelectrophorectic and immunohistochemical characterizations of fibrinogen derivatives in atherosclerotic aortic intimas and vascular prosthesis pseudo-intimas. Am J Pathol 141:861880.

van der Wal AC, Becker AE, van der Loos CM, and Das PK (1994). Site of intimal rupture or erosion of thrombosed coronary atherosclerotic plaques is characterized by an inflammatory process irrespective of the dominant plaque morphology. Circulation 89:36-44.

Wight TN, Raugi GJ, Mumby DM, and Bornstein P (1985). Light microscopic immunolocation of thrombospondin in human tissues. J Histochem Cytochem 33:285-302.

Wu C and Chung AE (1991). Potential role of entactin in hemostasis. Specific interaction of entactin with fibrinogen $A$ alpha and B beta chains. J Biol Chem 266:18802-18807.

Zhang Y, Cliff WJ, Schoefl GI, and Higgins G (1993). Immunohistochemical study of intimal microvessels in coronary atherosclerosis. Am J Pathol 143:164-172. 